\title{
Tema gerador, investigação e abordagem temática: um panorama da literatura
}

Generative theme, thematic investigation and approach: a literature panorama

Generando tema, investigación y enfoque temático: una visión general de la literatura

Recebido: 30/04/2020 | Revisado: 02/05/2020 | Aceito: 06/05/2020 | Publicado: 07/05/2020

Clarissa de Oliveira Garcia França

ORCID: https://orcid.org/0000-0003-4935-5905

Centro Federal de Educação Tecnológica - Rio de Janeiro, Brasil

E-mail: clarissagarcia17@gmail.com

Marcília Elis Barcellos

ORCID: https://orcid.org/0000-0002-5042-2311

Centro Federal de Educação Tecnológica - Rio de Janeiro, Brasil

E-mail: marcilia.barcellos@ @efet-rj.br

\section{Resumo}

Apresentamos nesse trabalho uma revisão bibliográfica sobre investigação temática e temas geradores de Paulo Freire. Essa revisão se deu a partir da busca de trabalhos que dissertassem sobre tema gerador, investigação ou abordagem temática no ensino de ciências e que estivessem presentes nos últimos 20 anos em revistas A1 e A2 do cenário nacional. A análise culminou na classificação e na interpretação dos artigos, relacionando-os a teoria freireana. Após a execução das análises, identificamos diferentes formas de abordagens e variações acerca da interpretação da teoria de Paulo Freire. O objetivo deste trabalho é conhecer um pouco mais da teoria de Freire e através da busca, categorização e análises dos artigos compreender como está sendo realizado o ensino de ciências através de temas geradores no país. Podemos concluir que por meio da pesquisa foi possível conhecer os obstáculos, dificuldades e vantagens encontradas no trato da teoria freireana e de que forma é possível realizá-la.

Palavras-chave: Paulo Freire; Ensino de Ciências; Tema gerador. 


\section{Abstract}

In this work, we present a bibliographic review on thematic research and generative themes by Paulo Freire. This review was based on the search for papers that spoke on generative theme, research or thematic approach in science education and that were present in the last 20 years in A1 and A2 magazines on the national scene. The analysis culminated in the classification and interpretation of the articles, relating them to Freire's theory. After performing the analyzes, we identified different forms of approaches and variations regarding the interpretation of Paulo Freire's theory. The objective of this work is to know a little more about Freire's theory and through the search, categorization and analysis of the articles, to understand how science teaching is being carried out through generative themes in the country. We can conclude that through the research it was possible to know the obstacles, difficulties and advantages found in dealing with Freire's theory and how it is possible to execute it.

Keywords: Paulo Freire; Science teaching; Generative theme.

\section{Resumen}

En este trabajo, presentamos una revisión bibliográfica sobre investigación temática y generación de temas por Paulo Freire. Esta revisión se basó en la búsqueda de artículos que hablaran sobre un tema generativo, investigación o enfoque temático en educación científica y que estuvieran presentes en los últimos 20 años en las revistas A1 y A2 en la escena nacional. El análisis culminó en la clasificación e interpretación de los artículos, relacionándolos con la teoría de Freire. Después de realizar los análisis, identificamos diferentes formas de enfoques y variaciones con respecto a la interpretación de la teoría de Paulo Freire. El objetivo de este trabajo es conocer un poco más sobre la teoría de Freire y, a través de la búsqueda, categorización y análisis de los artículos, comprender cómo se lleva a cabo la enseñanza de las ciencias a través de la generación de temas en el país. Podemos concluir que a través de la investigación fue posible conocer los obstáculos, dificultades y ventajas que se encuentran al tratar con la teoría de Freire y cómo es posible llevarla a cabo.

Palabras clave: Paulo Freire; Enseñanza de las Ciencias; Generando tema.

\section{Introdução}

Nos dias de hoje, crescentemente, debatemos sobre a necessidade de uma formação que seja capaz não só de aprimorar e abordar conteúdos e conceitos, mas também atitudes e 
práticas e, com isso, ser capaz de despertar nos alunos um olhar mais crítico sobre os fenômenos e acontecimentos que cercam seu contexto.

De acordo com Freire, uma das maneiras de auxiliar a formação dos estudantes e consequentemente o processo de transformação da sociedade sem abrir mão dos conteúdos curriculares é através da inclusão de temas geradores que possam ao mesmo tempo abordar a realidade do aluno constituindo assim uma nova estrutura curricular na escola. Para tanto é necessário que ocorra primeiramente uma investigação temática na qual será possível escolher temas que estejam de acordo com a realidade e necessidades da comunidade escolar.

Esta investigação implica, necessariamente, numa metodologia que não pode contradizer a dialogicidade da educação libertadora. Daí que seja igualmente dialógica. Daí que, conscientizadora também, proporcione, ao mesmo tempo, a apreensão dos "temas geradores" e a tomada de consciência dos indivíduos em torno dos mesmos. (Freire, 1987, p, 50).

A questão principal de nossa pesquisa será selecionar artigos em revistas nacionais da área de ensino de ciências com Qualis A1 e A2 que utilizem a investigação temática freireana no processo de ensino aprendizagem.

Após a busca dos artigos faremos classificações baseadas nos conteúdos dos mesmos, seguida de uma análise crítica para verificar se as pesquisas de fato se aproximam dos ideais preconizados por Freire.

Dessa forma, o objetivo do presente estudo é repensar o ensino de ciências, acrescentando ao mesmo temáticas de expressão para o corpo discente, fazendo com que os conteúdos sejam vinculados a realidade da comunidade escolar, tornando assim, o ensino mais atrativo e transformador para esses alunos.

\section{Tema Gerador e Investigação Temática}

O ensino por meio dos temas geradores e da investigação temática pode estimular e incentivar a troca de experiências e de conhecimento por meio do diálogo, respeitando as distinções, diferenças e particularidades de cada sujeito e sua percepção de mundo próprias. A proposta freireana tem por objetivo a superação de uma visão de mundo ingênuo para a construção de uma consciência crítica, fazendo com que o educando se assuma como sujeito responsável pela sua trajetória pessoal e se conscientize diante da realidade sócio histórica 
comum a todos. A educação problematizadora é o resultado prático da forma de ensino baseada nos conceitos de investigação temática e do tema gerador.

Será a partir da situação presente, existencial, concreta, refletindo o conjunto de aspirações do povo, que poderemos organizar o conteúdo programático (...) É na realidade mediatizadora, na consciência que dela tenhamos educadores e povo, que iremos buscar o conteúdo programático da educação.O momento deste buscar é o que inaugura o diálogo da educação como prática da liberdade. É o momento em que se realiza a investigação do que chamamos de universo temático do povo ou o conjunto de seus temas geradores.O que se pretende investigar, realmente, não são os homens, como se fossem peças anatômicas, mas o seu pensamento-linguagem referido à realidade, os níveis de sua percepção desta realidade, a sua visão do mundo, em que se encontram envolvidos seus "temas geradores". (Freire, 1987, p. 55-56)

Segundo Freire, (1987) o conceito de tema gerador não é uma criação arbitrária, ou uma hipótese de trabalho que deva ser comprovada ou constatada, essa concretização é resultado de experiências existenciais e reflexões críticas acerca das relações homem-mundo e homem-homem, ou seja, o tema gerador é concebido através das relações e de experiências próprias. Ainda segundo Freire, por meio do tema gerador pode-se gerar um conteúdo relacionado diretamente ao contexto de vida do educando a partir do qual será possível realizar uma reflexão crítica da realidade e uma intervenção na mesma.

Para melhor entendimento de nossa pesquisa, faz-se necessário esclarecer o que definimos por temas geradores e sua respectiva busca. Dessa forma, iremos entender como tema gerador, a temática que de fato represente a necessidade e a realidade de uma comunidade específica e a busca efetiva do tema gerador será considerada no trabalho que verdadeiramente respeitar a teoria e os pressupostos freireanos pela busca do mesmo, utilizando genuinamente as etapas da investigação temática (aproximação com a comunidade, círculos de cultura, processo de codificação e decodificação, além da redução temática) freireana para o encontro do tema. A investigação temática é um esforço para a consciência da realidade, ponto de partida do processo educativo.

Esta, à base da qual se pretende elaborar o programa educativo, em cuja prática educadores-educandos e educandos-educadores conjuguem sua ação cognoscente sobre o mesmo objeto cognoscível, tem de fundar-se, igualmente, na reciprocidade da ação. E agora, da ação mesma de investigar. A investigação temática, que se dá no domínio do humano e não no das coisas, não pode reduzir se a um ato mecânico. Sendo processo de busca, de conhecimento, por isto tudo, de criação, exige de seus sujeitos que vão descobrindo, no encadeamento dos temas significativos, a interpenetração dos problemas. (Freire, 1987, p.64) 
Através das referências de Freire e a partir da leitura da Pedagogia do Oprimido podemos, explicar três etapas fundamentais da teoria de investigação temática.A primeira etapa é a observação da realidade: significa problematizar a prática concreta da comunidade a ser trabalhada. Por meio do diálogo com esses sujeitos, identificar os conflitos e contradições de suas situações-limite, buscando fazer revelar sua temática significativa, sua realidade.

A segunda etapa é composta pela análise crítica: é o momento em que nos distanciamos da prática para nos aprofundarmos na compreensão das hipóteses levantadas na problematização inicial. É a oportunidade de buscar as razões de ser das suspeitas iniciais, através da ajuda de aportes teórico/práticos que tornem possível confrontar e superar o conhecimento anterior. Proporcionando dessa forma a compreensão das situações-limite em sua totalidade e o vislumbre da nova realidade que se quer construir.

A terceira etapa compreende a elaboração de propostas de ação. Esse momento engloba as hipóteses coletivas e dialógicas de ações, desde a mais próxima e subjetiva situação até a de maior dimensão. Com a perspectiva de superação das contradições sociais evidenciadas nos temas geradores, levantados e analisados com os participantes da investigação nos momentos anteriores. Os conhecimentos produzidos irão nos mostrar as possíveis soluções ou ações para melhora dos para os problemas enfrentados, oportunizando uma possível transformação daquela realidade.

Todas essas etapas irão auxiliar na busca do objetivo final, que é repensar o ensino através da busca das situações-limite e das as verdadeiras motivações da comunidade em questão.

\subsection{Metodologia}

A pesquisa realizada tem caráter bibliográfico do tipo estado do conhecimento, cujo objetivo é mapear e discutir a produção acadêmica em torno do assunto investigação temática, abordagem temática e temas geradores no ensino de ciências. Segundo Morosini, compreende-se estado do conhecimento:

[...] estado de conhecimento é identificação, registro, categorização que levem à reflexão e síntese sobre a produção científica de uma determinada área, em um determinado espaço de tempo, congregando periódicos, teses, dissertações e livros sobre uma temática específica. (Morosini, 2015, p.102). 
Foi realizada uma busca por revistas nacionais da área de ensino de ciências com Qualis A1 e A2. Foram selecionadas 91 revistas cujo conteúdo se encontrava disponível gratuitamente na internet. Dessas 91 revistas temos: 27 com Qualis A1, 64 com Qualis A2 classificadas pela Coordenação de Aperfeiçoamento de Pessoal de Nível Superior (CAPES) no triênio de 2013 a 2016. Como objeto da pesquisa foram considerados todos os números publicados desde o início da publicação de cada uma das revistas pesquisadas. Os artigos dessas revistas foram selecionados a partir da busca em títulos, palavras-chaves e/ou resumos que continham os termos "investigação temática", "abordagem temática" e/ou "tema gerador".

Após a busca citada anteriormente: das 91 revistas foram selecionados 25 artigos. As revistas cujos artigos foram selecionados são: Ciência \& Educação; Educação e Realidade; Educação em Revista; Ensaio: Pesquisa em Educação em Ciências; Revista Brasileira de Ensino de Física; Acta Scientiae: Revista de Ensino de Ciências e Matemática; Alexandria; Amazônia - Revista de Educação em Ciências e Matemáticas; Areté - Revista Amazônica de Ensino de Ciências; Caderno Brasileiro de Ensino de Física; Investigações em Ensino de Ciências; Praxis; Reflexão e Ação; Revista Brasileira de ensino de Ciência e Tecnologia e Revista de Educação, Ciências e Matemática. Podemos observar a relação de artigos, e seus respectivos periódicos no Quadro 1. 
Quadro 1. Artigos e periódicos.

\begin{tabular}{|c|c|c|c|}
\hline Título do Artigo & Periódico & Ano & $\begin{array}{l}\text { Código do } \\
\text { artigo }\end{array}$ \\
\hline $\begin{array}{l}\text { A interdisciplinaridade no ensino das ciências a partir de } \\
\text { uma perspectiva histórico-filosófica }\end{array}$ & $\begin{array}{l}\text { Caderno Brasileiro de } \\
\text { Ensino de Física }\end{array}$ & 1998 & A01 \\
\hline $\begin{array}{l}\text { Configurações curriculares mediante o enfoque CTS: } \\
\text { desafios a serem enfrentados na educação de jovens e } \\
\text { adultos }\end{array}$ & Ciência \& Educação & 2007 & A02 \\
\hline $\begin{array}{l}\text { Articulação Centro de Pesquisa - Escola Básica: } \\
\text { contribuições para a alfabetização científica e } \\
\text { tecnológica }\end{array}$ & $\begin{array}{l}\text { Revista Brasileira de } \\
\text { Ensino de Física }\end{array}$ & 2010 & A03 \\
\hline $\begin{array}{l}\text { Possibilidades de articulação teoria-e-prática por meio da } \\
\text { investigação colaborativa: uma proposta para o ensino de } \\
\text { matemática }\end{array}$ & $\begin{array}{l}\text { Amazônia - Revista de } \\
\text { Educação em Ciências }\end{array}$ & 2011 & A04 \\
\hline $\begin{array}{l}\text { Abordagem de temas no ensino médio: compreensões de } \\
\text { professores de física }\end{array}$ & Revista Ensaio & 2012 & A05 \\
\hline $\begin{array}{c}\text { Depressão e Antidepressivos: temas geradores para a } \\
\text { discussão de conceitos químicos no nível médio de } \\
\text { ensino }\end{array}$ & $\begin{array}{l}\text { Revista Brasileira de } \\
\text { ensino de Ciência e } \\
\text { Tecnologia }\end{array}$ & 2013 & A06 \\
\hline $\begin{array}{l}\text { Pesquisa participante como abordagem metodológica no } \\
\text { ensino: aprendizado de matemática e educação ambiental }\end{array}$ & $\begin{array}{l}\text { Investigações em Ensino } \\
\text { de Ciências }\end{array}$ & 2014 & A07 \\
\hline $\begin{array}{l}\text { Considerações acerca do ensino de Ciências nos anos } \\
\text { iniciais do Ensino Fundamental }\end{array}$ & Práxis & 2014 & A08 \\
\hline $\begin{array}{l}\text { Investigação Temática no Contexto do Ensino de } \\
\text { Ciências: Relações entre a Abordagem Temática } \\
\text { Freireana e a Práxis Curricular via Tema Gerador }\end{array}$ & Alexandria & 2014 & A09 \\
\hline $\begin{array}{l}\text { Educação do Campo: formação em ciências da natureza } \\
\text { e o estudo da realidade }\end{array}$ & Educação \& Realidade & 2015 & A10 \\
\hline $\begin{array}{l}\text { Concepções dos professores de ciências no ensino } \\
\text { fundamental sobre a educação ambiental }\end{array}$ & $\begin{array}{l}\text { Revista Amazônica de } \\
\text { Ensino de Ciências }\end{array}$ & 2015 & A11 \\
\hline $\begin{array}{c}\text { Avanços alcançados por professores na implementação } \\
\text { da abordagem temática em uma escola pública estadual } \\
\text { do interior do RS }\end{array}$ & Educação em Revista & 2016 & A12 \\
\hline
\end{tabular}


Research, Society and Development, v. 9, n. 7, e145974126, 2020

(CC BY 4.0) | ISSN 2525-3409 | DOI: http://dx.doi.org/10.33448/rsd-v9i7.4126

\begin{tabular}{|c|c|c|c|}
\hline $\begin{array}{c}\text { Situações-limite na formação de professores de ciências } \\
\text { na perspectiva freireana: da percepção da realidade à } \\
\text { dimensão pedagógica }\end{array}$ & $\begin{array}{c}\text { Investigações em Ensino } \\
\text { de Ciências }\end{array}$ & 2016 & A13 \\
\hline $\begin{array}{l}\text { O Despertar para uma Cultura de Participação no } \\
\text { Trabalho com um Tema Gerador }\end{array}$ & Alexandria & 2016 & A14 \\
\hline $\begin{array}{c}\text { Tema Gerador e a Relação Universidade-Escola: } \\
\text { Percepções de Professoras de Ciências de uma Escola } \\
\text { Pública em Ilhéus-BA }\end{array}$ & Alexandria & 2016 & A15 \\
\hline $\begin{array}{l}\text { Investigação temática na formação de professores de } \\
\text { ciências em Pau Brasil-BA: compreensões acerca de um } \\
\text { tema gerador }\end{array}$ & Revista Ensaio & 2016 & A16 \\
\hline $\begin{array}{c}\text { Da xícara ao Becker: plantas medicinais como recurso } \\
\text { didático no ensino de química }\end{array}$ & $\begin{array}{l}\text { Revista de Educação, } \\
\text { Ciências e Matemática }\end{array}$ & 2016 & A17 \\
\hline $\begin{array}{c}\text { O tabaco utilizado como tema gerador no ensino de } \\
\text { Química em região economicamente dependente dessa } \\
\text { cultura }\end{array}$ & Acta Scientiae & 2017 & A18 \\
\hline $\begin{array}{l}\text { Temas geradores através de uma abordagem temática } \\
\text { Freireana: Contribuições para o ensino de ciências }\end{array}$ & $\begin{array}{l}\text { Revista de Educação, } \\
\text { Ciências e Matemática }\end{array}$ & 2017 & A19 \\
\hline $\begin{array}{c}\text { Os três momentos pedagógicos como estruturantes de } \\
\text { currículos: O estudo da realidade e os temas geradores na } \\
\text { educação em ciências }\end{array}$ & Reflexão e Ação & 2018 & A20 \\
\hline $\begin{array}{l}\text { A Rede Temática e o Ciclo Temático na Busca pela } \\
\text { Cultura de Participação na Educação CTS }\end{array}$ & Alexandria & 2018 & A 21 \\
\hline $\begin{array}{c}\text { Educação Ambiental crítica e arte participativa: a } \\
\text { construção de reflexão e ação em uma escola da Baixada } \\
\text { Fluminense }\end{array}$ & $\begin{array}{l}\text { Amazônia - Revista de } \\
\text { Educação em Ciências }\end{array}$ & 2018 & A22 \\
\hline $\begin{array}{l}\text { Milton Santos e Paulo Freire na educação em ciências: a } \\
\text { forma-conteúdo expressa no tema gerador }\end{array}$ & $\begin{array}{c}\text { Investigações em Ensino } \\
\text { de Ciências }\end{array}$ & 2018 & A23 \\
\hline $\begin{array}{c}\text { Desafios e potencialidades em intervenções curriculares } \\
\text { na perspectiva da abordagem temática }\end{array}$ & $\begin{array}{c}\text { Ensaio: Pesquisa em } \\
\text { Educação em Ciências }\end{array}$ & 2019 & A24 \\
\hline $\begin{array}{c}\text { Elementos da abordagem temática no Ensino Médio: } \\
\text { sinalizações para formação de professoras e de } \\
\text { professores }\end{array}$ & Ciência \& Educação & 2019 & A25 \\
\hline
\end{tabular}

Fonte: Autores. 
Todos estes artigos passaram a compor a base da qual iremos extrais as informações para as análises e discussões presentes neste trabalho, tornando-se nosso objeto de estudo.

\subsection{Metodologia de análise dos artigos}

Para realizar o estudo dos artigos selecionados iremos utilizar a metodologia de análise de conteúdo (AC). A mesma faz parte de uma metodologia de pesquisa que é utilizada para retratar, analisar e auxiliar a compreender o conteúdo de uma classe de documentos e textos. Assim, a partir dessa análise e através da organização do material em descrições sistemáticas, qualitativas ou quantitativas, é possível reinterpretar as mensagens e os textos e alcançar uma real compreensão de seus significados em um padrão que vai além de uma simples leitura. Segundo Bardin a análise de conteúdo consiste em:

Um conjunto de instrumentos metodológicos cada vez mais sutis em constante aperfeiçoamento, que se aplicam a "discursos" (conteúdos e continentes) extremamente diversificados. O fator comum destas técnicas múltiplas e multiplicadas - desde o cálculo de frequência que fornece dados cifrados, até a extração de estruturas traduzíveis em modelos - é uma hermenêutica controlada, baseada na dedução: a inferência. (Bardin, 2009, p. 15)

Nossa escolha por este método de análise pode ser explicada pelos artigos lidarem com grupos e comunidades e pela necessidade de ultrapassar as incertezas das hipóteses e pressupostos contidos nos estudos, pela necessidade de enriquecimento da leitura por meio da compreensão e das significações e por nossa obrigação de desvelar as relações e interpretações que se estabelecem além dos textos propriamente ditos.

Considerando que a abordagem qualitativa, enquanto exercício de pesquisa, não se apresenta como uma proposta rigidamente estruturada, ela permite que a imaginação e a criatividade levem os investigadores a propor trabalhos que explorem novos enfoques. (Godoy, 1995, p.23)

A AC pode ser desenvolvida a partir de três etapas: $1^{\mathrm{a}}$. A pré-análise; $2^{\mathrm{a}}$. A exploração do material; e, por fim, $3^{\text {a }}$. O tratamento dos resultados: a inferência e a interpretação. Assim, primeiramente, foi feita a leitura dos artigos, como pré-análise. Após a leitura dos textos realizamos a exploração e separação dos mesmos através da criação de categorias de pesquisa pertinentes ao interesse de nosso trabalho. Como última etapa, foi elaborada a conclusão e os 
resultados da análise por meio da escrita, tratamento e explicação do material, a partir da separação já realizada e de acordo com os objetivos pretendidos. Assim, afim de encontrar a atual situação das pesquisas relacionadas a Paulo Freire e temas geradores no contexto nacional e como essa abordagem tem sido desenvolvida, utilizaremos a metodologia da $\mathrm{AC}$ nos artigos encontrados.

Dos 25 artigos obtidos dos periódicos A1 e A2 que utilizam a abordagem temática e os temas geradores, nem todos utilizam como referencial teórico Paulo Freire, portanto, para fins de posterior análise e comparação faremos a divisão dos artigos em categorias (seções e subseções). Devemos esclarecer que para nossa pesquisa a seção de maior interesse é seção 1.1.3.2 que trata dos trabalhos que realizaram todas as etapas da investigação temática proposta por Paulo Freire e obtiveram um tema gerador emergido da comunidade. Não excluímos as outras categorias pois foram selecionadas de acordo com o critério de busca mencionado na seção 2.1 de metodologia desta pesquisa, além de também fazerem parte do campo de análise. Segue abaixo o quadro de classificação dos artigos:

Quadro 2. Divisões dos artigos

\begin{tabular}{|c|c|c|c|c|}
\hline \multicolumn{4}{|c|}{$\begin{array}{l}\text { Secão 1 } \\
\text { Artigos que citam Paulo Freire } \\
\text { (composta por } 20 \text { artigos })\end{array}$} & $\begin{array}{l}\text { Seção 2 } \\
\text { Artigos que não citam } \\
\text { Paulo Freire (composta por } \\
5 \text { artigos) }\end{array}$ \\
\hline \multicolumn{4}{|c|}{ Seção 1.1 -Trata-se de artigo que possuem pressupostos freireanos. } & $\begin{array}{l}\text { Seção 2.1 - Trata-se de } \\
\text { artigos que não abordam a } \\
\text { teoria freireana mas fazem } \\
\text { uso do termo "tema } \\
\text { gerador". (3 artigos) }\end{array}$ \\
\hline \multirow{2}{*}{$\begin{array}{l}\text { Seção 1.1.1 } \\
\text { Artigos } \\
\text { teóricos. } \\
\text { (6 artigos) }\end{array}$} & \multirow{2}{*}{$\begin{array}{c}\text { Seção 1.1.2 } \\
\text { Artigos } \\
\text { empíricos, } \\
\text { porém não tem } \\
\text { por objetivo a } \\
\text { busca pelo tema } \\
\text { gerador. } \\
\text { (6 artigos) }\end{array}$} & \multicolumn{2}{|c|}{$\begin{array}{l}\text { Seção 1.1.3 } \\
\text { Artigos empíricos que tem por objetivo a } \\
\text { busca pelo tema gerador ( } 9 \text { artigos })\end{array}$} & \multirow{2}{*}{$\begin{array}{l}\text { Seção } 2.2 \text { - Trata-se de } \\
\text { artigos que abordam o } \\
\text { universo da investigação de } \\
\text { temas, porém não abordam } \\
\text { a teoria freireana. } \\
\text { ( } 2 \text { artigos })\end{array}$} \\
\hline & & $\begin{array}{l}\text { Seção 1.1.3.1 } \\
\text { Trata-se de } \\
\text { artigos que } \\
\text { utilizam temas } \\
\text { geradores pré- } \\
\text { estabelecidos. } \\
\text { (2 artigos) }\end{array}$ & $\begin{array}{c}\text { Seção 1.1.3.2 } \\
\text { Trata-se de artigos que } \\
\text { realmente realizam todas } \\
\text { as etapas freireanas pela } \\
\text { busca do tema gerador. } \\
\text { (7 artigos) }\end{array}$ & \\
\hline
\end{tabular}

Fonte: Autores. 


\section{Discussão}

Após a elucidação da metodologia de busca dos artigos e da metodologia que iremos utilizar para analisar os mesmos, entramos na fase de exploração dos trabalhos selecionados. Nesta etapa de nossa pesquisa para facilitar o entendimento faremos a discussão separada pelas categorias apresentadas no Quadro 2.

\section{- Seção 1}

Nesta seção iremos analisar 20 artigos que utilizam pressupostos da teoria de Paulo Freire e que irão influenciar a forma com que será abordado o ensino de ciências.

A motivação para essa classificação se deu de acordo com o interesse de nossa pesquisa, que visa analisar quais artigos de fato utilizam as etapas da investigação temática para a busca do tema gerador. Sendo assim, a seção 1.1 analisa os artigos freireanos e possui 3 subdivisões, a primeira (seção 1.1.1) conta com seis trabalhos e refere-se as pesquisas que versam sobre a busca do tema gerador de forma teórica. A segunda (seção 1.1.2) também possui seis artigos e irá tratar das pesquisas que utilizaram meios empíricos de investigação para outros fins, como por exemplo entrevistas com docentes, porém, apesar de utilizarem esta metodologia, os mesmos não realizam a busca pelo tema gerador em um local ou em uma comunidade específica. A terceira, (seção 1.1.3) que conta com nove trabalhos, trata dos artigos que realmente se propõem a realizar a busca pelo tema gerador em uma escola ou comunidade específica, porém, realizamos outra divisão, pois foi possível observar que dos trabalhos encontrados alguns (seção 1.1.3.1) realizaram um processo de busca, porém já tinham pré-estabelecido um tema gerador e outros (seção 1.1.3.2) verdadeiramente efetuaram todas as etapas da investigação temática proposta por Paulo Freire e trabalharam de fato com o tema gerador emergido através da busca na comunidade.

\section{- Seção 1.1.1}

Nesta seção iremos fazer a discussão dos artigos que utilizaram a teoria freireana, porém não realizaram pesquisas empíricas, apenas a discussão teórica do assunto. Os artigos selecionados nesta categoria são: A01, A02, A10, A20 e A24.

$\mathrm{O}$ artigo A01 aborda o aprofundamento das reflexões e práticas docentes, além de trocas de experiências no curso Racionalização de Combustíveis. Também versa sobre a questão da interdisciplinaridade e considera uma abordagem histórico-filosófica do conhecimento como forma de levar os estudantes a compreender o mundo que os cerca. $\mathrm{O}$ 
tema, Energia, foi estudado, porém, não houve pesquisa ou investigação, pois o artigo não versa sobre uma localidade ou comunidade específica e sim sobre teorias de práticas docentes no ensino secundário em geral. A escolha do tema para que as práticas fossem desenvolvidas se deu pensando em um conteúdo que pudesse ser amplamente trabalhado por diversas disciplinas e que apresentasse grande relevância na sociedade e na compreensão da realidade. Neste trabalho, a pesquisa foi classificada como teórica, apesar de abordar o tema energia, pois o foco foi estudar práticas já realizadas e enfatizar a troca de experiências entre os docentes.

No artigo: A02 são abordadas intervenções curriculares com foco em CTS e temáticas contemporâneas. O objetivo do trabalho foi identificar e discutir posicionamentos de professores de EJA, quanto a utilização de temas relevantes em suas aulas. O trabalho não abordava um contexto específico, portanto não houve a escolha de um tema, mas utilizando o referencial de Paulo Freire o mesmo estabeleceu discussões e implicações importantes para o campo curricular e para a formação de professores.

Em A10 são estudados projetos de reorientação curricular sob a perspectiva de Paulo Freire para constituição de práticas docentes na educação no campo. Neste trabalho, não existe um tema, e sim um estudo sobre a busca desses temas relacionados a questão da formação docente e sobre a educação no campo e como essas novas práticas podem ser efetivas para um estudo da realidade por meio da investigação temática, portanto classificamos este artigo como teórico.

No trabalho A20 são apresentados os resultados obtidos a partir de três processos formativos que envolveram seis escolas públicas, e professores de biologia, química e física no estudo da realidade para chegar aos temas geradores a partir da utilização dos Três Momentos Pedagógicos como estruturantes de currículos.

A proposta dos Três Momentos Pedagógicos (3 MP) é utilizada atualmente em diversos projetos de ensino. Sua estrutura é composta de uma problematização inicial, organização, e aplicação do conhecimento. A dinâmica dos 3MP pode ser classificada como uma adaptação do processo de investigação temática apresentado anteriormente apresentado no segmento tema gerador e investigação temática.

O trabalho A20 utiliza como referencial Delizoicov, Angotti e Pernambuco através da proposta dos 3MP, logo, consideramos o artigo válido em nossa pesquisa pelo mesmo também abordar as ideias de Paulo Freire e devido aos 3MP serem baseados no referencial freireano. O tema é escolhido de acordo com a metodologia dos mesmos, atentando para as necessidades e características da comunidade (um município de São Paulo), utilizando esses 
conhecimentos em um projeto interdisciplinar. Classificamos esta pesquisa na seção de artigos teóricos, pois os temas encontrados foram desenvolvidos previamente nas escolas citadas, o artigo em si não reproduz todas as etapas da investigação temática, mas apenas comenta sobre as investigações que ocorreram nas respectivas escolas mencionadas e seus resultados.

$\mathrm{O}$ artigo A24 se propõe a investigar o processo da abordagem temática e como se dá uma intervenção curricular. Quais são as dificuldades e fragilidades, principalmente na visão de professores de ciências da natureza. São abordados a identificação, a análise e a socialização de formas curriculares, na área de ciências da natureza, e sua abordagem temática. Dessa forma, é possível a constituição de currículos estruturados nesta perspectiva. A análise mencionada foi realizada com professores do ensino médio de escolas estaduais do Rio Grande do Sul. O artigo não trata da busca de um tema por isso foi classificado como teórico.

\section{-Seção 1.1.2}

Nesta seção iremos fazer a discussão dos artigos empíricos, que utilizam a teoria freireana, porém, a pesquisa neles contida não tem por objetivo a busca pelo tema gerador. A05, A12, A13, A18, A22 E A25 foram os artigos selecionados.

No artigo A05 é apresentada uma discussão dos limites e possibilidades da abordagem temática no contexto educacional brasileiro, através da análise de compreensões de professores da educação básica. $\mathrm{O}$ artigo não aborda um contexto específico e sim um campo mais abrangente, escolas da região metropolitana de São Paulo. A pesquisa explicita possibilidades da abordagem de temas vinculados a resolução de problemas e de resolução de questões pertencentes ao mundo e ao contexto dos alunos. Foi classificada como empírica, pois tem por objetivo problematizar e aprofundar compreensões dos professores sobre a abordagem de temas, resolução de problemas e discussões a respeito do tema CTS (ciência, tecnologia e sociedade) e não tem como foco a busca pelo tema gerador.

No segundo artigo selecionado A12 foram feitas investigações e análises sobre as compreensões e percepções de professores de uma escola pública estadual do Rio Grande do Sul, sobre os benefícios e avanços obtidos na implementação de intervenções curriculares pautadas na abordagem temática. Neste artigo não há a escolha de um tema propriamente dito, e sim a discussão acerca de alguns temas em geral e sua implementação na prática.

No artigo A13 aborda a investigação de situações-limite de professores no contexto da utilização de temas geradores, mais especificamente professores de ciências do ensino 
fundamental II. A pesquisa foi estruturada de acordo com a abordagem freireana e realizada principalmente sob o ponto de vista dos docentes. Chegando ao tema "O perigo do rio Água Preta em Pau brasil-BA”. Este artigo foi classificado como empírico, porém sem busca de tema, pois todo o artigo está voltando para as percepções dos professores apenas e não de toda comunidade escolar que os cerca, o foco do texto está na análise das situações limite do processo educativo e não da busca do tema propriamente dito.

O estudo A18 ressalta que o ensino de química deve proporcionar aos alunos o interesse pela ciência, favorecer o pensamento crítico e a consciência cidadã. Apresenta a proposta de um ensino atrelado aos interesses dos alunos, afim de oportunizar uma aprendizagem significativa. Dessa forma, foi utilizado o tema gerador Tabaco, com o objetivo de priorizar o contexto estudantil nas aulas de química. O tema foi utilizado devido ao contexto escolar, priorizando o contexto dos estudantes, alunos do município da região do Vale do Rio Pardo/RS, economicamente dependente da cultura do fumo. O resultado da pesquisa é utilizado para direcionamento das aulas e contextualização do tema previamente escolhido. O trabalho também buscou utilizar a realidade local e a principal fonte de renda das famílias do município, na qual todos os estudantes e suas famílias estão ligados de forma direta ou indireta. Foi classificado nesta seção, pois apesar de conter uma pesquisa, não realiza de fato a busca pelo tema gerador, se baseia nas características da cidade para atribuir um tema específico aos alunos, ou seja, não realiza a investigação temática.

No artigo A22, é tratada a temática da educação ambiental crítica através da prática de elementos cognitivos e afetivos, a partir da análise de questões locais e da participação coletiva dos envolvidos de uma escola na Baixada Fluminense. A escolha do tema de trabalho, educação ambiental, foi definido de forma prévia, porém, foram considerados aspectos da comunidade escolar, relatos e encontros interativos, através de pesquisa participante. O objetivo do estudo foi reconhecer as possibilidades e limitações do trabalho com a educação ambiental crítica e artes dentro da realidade da escola pública. $\mathrm{O}$ artigo foi classificado nesta seção pois apesar de apresentar uma pesquisa na comunidade, o objetivo do trabalho foi a discussão do tema (escolhido de forma prévia) educação ambiental, e não a busca pelo mesmo.

No último artigo selecionado A25 são abordados temas relevantes para a ação de professores de Física que participaram do processo de pesquisa e discussão da abordagem temática. Foi feita a análise dos dados em relação a natureza dos temas e o critério de seleção das temáticas. Classificamos o A25 nesta categoria pois a pesquisa aborda temas de ensino de física em geral e a compreensão dos professores sobre as possibilidades da abordagem desses 
temas no Ensino Médio. Relacionando-os a resolução de problemas, desafios e possiblidades. Não é realizada a busca por um tema gerador em uma comunidade específica

\section{-Seção 1.1.3}

Nesta divisão iremos explorar os trabalhos encontrados nas revistas citadas com foco na escolha do tema de acordo com cada artigo. Ou seja, tratam-se de artigos empíricos que tem por objetivo a busca pelo tema gerador. Dessa forma, além da investigação e da busca do conteúdo do artigo iremos verificar se a utilização e o encontro dos temas geradores foram feitos através uma pesquisa democrática pela demanda da comunidade, se foi baseada no contexto dos alunos ou se foi escolhido por critérios outros, sem nenhum tipo de consulta à comunidade.

\section{-Seção 1.1.3.1}

Nesta subseção analisaremos os artigos que utilizam temas geradores préestabelecidos, ou seja, que na prática não realizaram todas as etapas de investigação temática segundo os pressupostos freireanos, ou se realizaram não adotaram o tema o encontrado. Enfatizamos que esses trabalhos se denominam pesquisas de abordagem freireana mas no nosso entendimento contrariam a ideia básica da investigação temática freireana, que é busca da situação limite do local ou da comunidade para futura compreensão e busca por mudança e transformação. Fazem parte dessa categoria os artigos A07 e A08.

No estudo A07 foi feita a escolha prévia do tema gerador, água, que será relacionado ao cotidiano dos alunos. Foi realizada uma investigação com uma forma de pesquisa participante no contexto educacional de uma escola pública do Rio de Janeiro, e os resultados apontaram práticas facilitadoras do aprendizado dos conteúdos a serem trabalhados. O tema foi escolhido previamente, de acordo com o contexto escolar, segundo os autores.

No segundo artigo A08 é realizada a investigação dos temas geradores nos anos iniciais do ensino fundamental (especificamente no ensino de ciências), com o objetivo de mobilizar a participação ativa dos educandos na construção do saber. Apesar de ter como objetivo da investigação dos temas, não houve pesquisa para escolha do tema. O tema escolhido (alimentação saudável), segundo os autores, ocorreu pelo fato estar presente no cotidiano dos alunos além de oferecer a possibilidade de se trabalhar diferentes conhecimentos da grade curricular do ensino médio.

Ao analisar os artigos anteriores, numa visão comparativa à abordagem freireana, podemos concluir que mesmo com o objetivo do encontro de temas e da abordagem temática, 
os trabalhos definiram de forma prévia o tema que seria trabalhado pela escola ou pela comunidade em questão.

Acreditamos que tais escolhas foram feitas pelas dificuldades de adaptação de certos temas a conteúdos específicos e pela facilidade de adaptação ao contexto a que a pesquisa está relacionada. Muitos trabalhos já possuíam em sua comunidade um cenário específico, como falta de água, poluição, forma econômica, ou temas do interesse em geral. Ou seja, o contexto e o cotidiano dos alunos e da comunidade ao redor foram algumas vezes priorizados, mas não houve busca de fato, pelo tema, com o envolvimento da comunidade.

Nestes exemplos, um dos fatores que contribuíram com a escolha do tema foram os conteúdos da disciplina. Ao observar o resultado dos trabalhos podemos concluir que mesmo com a definição prévia dos temas, os mesmos aparentam ter sido relevantes e terem contribuído para aquela região/comunidade específica.

\section{-Seção 1.1.3.2}

Nesta subseção analisaremos os artigos que realizaram a busca pelos temas geradores, ou seja, trabalhos que realizaram todas as etapas de investigação temática segundo os pressupostos freireanos e mesmo obtendo os mais diversos temas os utilizaram na realidade do aluno, ou seja, os docentes empregaram o tema obtido articulado com os conteúdos curriculares. Essa é a subseção de maior importância para nossa pesquisa, pois através dela poderemos obter um panorama de como a abordagem vem sendo feita, seus principais desafios e dificuldades, além de seus principais acertos. Podemos destacar que do total de 25 artigos selecionados para a análise apresentada, apenas 7 artigos de fato realizaram a teoria freireana, do modo com a entendemos e definimos anteriormente. São eles os trabalhos: A09, A14, A15, A16, A19, A21 e A23.

O trabalho A09 utilizou de fato as etapas da abordagem/ teoria temática freireana com a práxis curricular e encontrou o tema relacionado ao consumo de água na comunidade em questão. Além da proposta de investigação temática freireana, os autores associaram a mesma à dinâmica de construção da Práxis Organizativa Curricular via tema gerador de SILVA (2004) adaptando as etapas de abordagem temática freireana a 5 momentos (com a diferença para Freire da inserção dos Momentos I e V, onde no Momento I são realizadas aproximações iniciais com a comunidade escolar e no Momento $\mathrm{V}$ a reorganização coletiva da escola a partir do fazer pedagógico). Também foi utilizada a Análise Textual Discursiva para a investigação dos dados obtidos. Assim, através do processo abordado foi estabelecido o tema "Consumo de água na comunidade Banco da Vitória". 
No trabalho A14 há a discussão da busca pelo tema gerador a partir de uma reorientação curricular na perspectiva da abordagem temática, utilizando a dinâmica dos três momentos pedagógicos (3MP). As temáticas e os desafios encontrados foram resolvidos/destinados a professores de ciências (biologia, física e química). Mesmo a pesquisa utilizando o referencial teórico dos 3MP, já abordado anteriormente, iremos considera-lo como de abordagem freireana, pois essa metodologia tem origem na teoria de Paulo Freire. $\mathrm{O}$ artigo tem como um dos objetivos o despertar para uma cultura de participação da população.

$\mathrm{O}$ artigo A14 por meio da utilização da dinâmica dos 3 MP chega ao tema "Arroio Cadena: Cartão Postal de Santa Maria?". O mesmo apresentou uma capacidade de ser problematizado e considerou as situações, demandas e problemas locais. O artigo também demonstra a importância do reconhecimento da comunidade local da escola, das percepções individuais e coletivas dos problemas da comunidade e que transformações são necessárias para modificar essa situação, destacando a importância do currículo neste momento.

Em A15 são investigadas as contribuições e dificuldades de se construir atividades que são originadas de um tema gerador. Essa pesquisa é feita por professores da educação básica em conjunto com a Universidade Estadual de Santa Cruz. O trabalho em questão se baseia na abordagem freireana para a escolha do tema e também aborda questões como condições para a implementação do tema escolhido nas escolas.

São utilizadas em A15 as 5 etapas do processo de investigação temática freireana, além da Práxis Curricular via tema gerador de SILVA (2004) que comentamos anteriormente. Os professores participantes da pesquisa também puderam apontar os principais desafios e contribuições da implementação do tema gerador na construção de atividades didáticopedagógicas. Os mesmos também elaboraram um quadro-síntese com o tema "Condições para o planejamento e implementação da proposta" e "Pareceria Universidade-Escola". Com isso foi possível a organização dos temas: "Consumo de água na comunidade do Banco da Vitória" e "Consumo consciente de água".

No artigo A16 foi desenvolvido um processo formativo de professores de ciências, que abordava a relação entre a investigação temática freireana e a práxis curricular através do tema gerador. Foram analisadas as compreensões dos professores acerca da seleção do tema gerador: "O perigo do rio Água Preta em Pau Brasil-BA". Esse artigo evidenciou a possibilidade de se repensar os pressupostos freireanos considerando particularidade $o$ contexto das escolas públicas. Também foi possível a compreensão dos professores na obtenção dos temas e na afirmação de que os mesmos são legitimados de acordo com os problemas específicos da comunidade. O trabalho também aponta para a necessidade de 
investigar e determinar como é possível contribuir com as atividades didático-pedagógicas e quais principais desafios de sua implementação.

No trabalho A19 foram apresentados os resultados acerca das implicações pedagógicas no processo de ensino aprendizagem de química e biologia, através da utilização de um tema gerador emergido no contexto de uma escola pública estadual. $\mathrm{O}$ artigo divide-se em duas etapas: a escolha de temas através da pesquisa com a comunidade e a problematização em torno dos dados para a legitimação do tema escolhido. Além dessas etapas pertencentes a teoria freireana, o trabalho apresenta atividades desenvolvidas com o tema escolhido, "Drogas". Para a escolha do tema foram realizadas todas as etapas da investigação temática, durante a execução das atividades com os alunos foram desenvolvidas atividades que pudessem colocar o aluno no centro do processo educativo.

O presente artigo também oportunizou a compreensão de que o processo de ensino aprendizagem através de um tema emergido da comunidade, favorece a formação de sujeitos que possam atuar de forma crítica, transformando a realidade em que vivem.

No artigo A21 ocorre o processo de investigação temática, suas contribuições e sua construção, no contexto de um processo formativo de educadores de ciências de um município na Bahia. Sobre o ciclo: "No que concerne às perspectivas teórico-metodológicas deste estudo, o Ciclo Temático apresenta-se como um elemento organizador de foco metodológico, estruturado na problematização e sistematização das causas.” (MILLI et al; 2018, p.26). Foram realizadas suposições de temas, e as situações foram problematizadas, visando desenvolver uma cultura de participação e reconhecimento dos problemas e demandas sociais. Dessa forma, através do ciclo temático foi possível expressar a relação entre as causas e consequências das ações analisadas e das situações limite, sendo possível realizar todas as etapas da investigação temática. Concluindo assim a elaboração de um plano de ensino que articula o conhecimento a ações de ordem política e desenvolvimento de uma cultura de participação social.

No trabalho A23 são exploradas as relações entre os ideais de Paulo Freire e do geógrafo Milton Santos, investigando assim as contribuições do conceito forma-conteúdo, estabelecido por Santos, na identificação de temas geradores. Assim, foi realizada uma pesquisa com professores dos anos iniciais, com foco em educação em ciências, visando o desenvolvimento das etapas da investigação temática.

$\mathrm{O}$ artigo ouve as vozes da comunidade em questão e define o tema de acordo com as necessidades do local, através da pesquisa e da investigação temática. O processo de obtenção dos temas geradores seguiu as etapas da investigação e incluiu aproximações com a 
comunidade, apresentações de situações-limite, legitimação da hipótese e por final uma reorganização da programação curricular, ou seja, o conteúdo programático foi reorganizado para que o tema gerador "Condições da feira nossa de cada dia: bairro de Fátima, Itabuna/BA" fosse trabalhando na unidade de ensino. A articulação entre os pressupostos teóricos de Freire e Milton Santos foram obtidas através de codificações, problematizações e descodificações. Como conclusão, os autores constataram que o conceito de forma-conteúdo de Santos potencializou o processo de investigação temática pois compreendeu como a localidade está intrinsicamente ligada às relações sociais e aos problemas vividos pelos sujeitos.

Logo, ao analisar os artigos acima citados, podemos constatar que apesar das dificuldades de adaptação do tema ao currículo escolar propriamente dito, é possível realizar a abordagem temática com um melhor conhecimento da comunidade em que se mora, esclarecimento e enfrentamento das dificuldades sociais e políticas, além da transformação da realidade local.

\section{- Seção 2}

Na seção 2 foram selecionados os artigos que utilizam modalidades de ensino temático mas não utilizam a teoria de Paulo Freire. As subseções aqui apresentadas se dividem em 2.1 e 2.2. Na seção 2.1 encontramos trabalhos que alegam utilizar o ensino temático atribuído a teoria freireana, porém não reconhecemos os mesmos de acordo com nosso entendimento. E na seção 2.2, apresentamos apenas os artigos que utilizaram o ensino por meio de temas em geral.

\section{- Seção 2.1}

Nesta seção iremos abordar os artigos que não desenvolvem a teoria freireana mas tomam posse do termo "tema gerador" em suas pesquisas. Ou seja, mesmo empregando explicitamente o uso do "tema gerador", os trabalhos em nenhum momento se referem a Paulo Freire, sua obra ou abordam a investigação temática. Em nosso entendimento o ensino temático tem sua importância no contexto escolar, porém, compreendemos que o termo "tema gerador" está atrelado necessariamente a uma abordagem crítica, de enfrentamento, mudança e transformação, típicas das abordagens freireanas. Portando os trabalhos aqui classificados são para nós trabalhos que se utilizam de um tema, mas não de um "tema gerador" de fato, apesar de se apropriarem desse termo. Os trabalhos dessa seção se diferenciam dos da seção 
1.1.3.1 porque sequer citam Paulo Freire ou autores correlacionados. São eles: A06, A11 e A17.

No artigo A06 é tratada a contextualização do ensino de química através de "temas geradores". Novamente, devemos esclarecer que embora no artigo se fale em "temas geradores", em nenhum momento há menção a teoria de Paulo Freire ou explicação da mesma. No trabalho existe a definição prévia do tema, depressão, fazendo assim a inclusão de temas sociais no currículo. Percebemos que a depressão foi escolhida como tema, por se tratar de um assunto de extrema relevância, por ser uma doença que atinge de 3\% a 5\% da população mundial e por ter várias teorias propostas com explicação em causas bioquímicas, o que é útil no ensino de química. Dessa forma, podemos observar que o tema, apesar de relevante, não foi escolhido de acordo com a necessidade da comunidade ou através de uma consulta ou pesquisa prévia.

No artigo A11, é abordada a questão do meio ambiente, problemas ambientais e a educação ambiental como tema gerador, após pesquisa qualitativa sobre o assunto. Como já explicado, foi utilizado no resumo o termo "tema gerador", apesar do trabalho não fazer menção a teoria freireana. A escolha de tal tema se deu através de entrevistas com a comunidade em questão, coleta de dados com os professores nas escolas, análise de dados do IBGE, e análise quantitativa dos dados. Os autores justificam essa escolha por tratarem-se de escolas localizadas tanto na zona urbana, quanto na zona rural do município de Monte Alegre, no estado do Pará. Segundo os autores o tema apresenta relevância no cotidiano e no contexto dos alunos. A metodologia do trabalho, incluiu a pesquisa que foi realizada com os professores, para posterior discussão de estratégias a serem utilizadas em sala de aula e visou uma possível universalização da prática nas escolas.

No trabalho A17 foi tratado o uso de plantas medicinais como tema no ensino de química, mais especificamente em aulas de estágio supervisionado, possibilitando aos alunos uma experiência diferenciada na abordagem dos conteúdos de química. O objetivo do trabalho visou contribuir com uma abordagem contextualizada para o ensino de química a partir de um tema comum, plantas medicinais.

\section{- Seção 2.2}

A seção em questão trata de artigos que abordam o universo da investigação de temas, ou seja, o ensino temático, porém não especificamente a teoria freireana. Fazem parte dessa seção os artigos A03 e A04. 
O artigo A03 versa sobre a organização e a seleção de conteúdos a seres abordados durante e após visitas a laboratórios de pesquisa em física da Universidade de São Paulo (USP), com alunos do ensino médio. A investigação visa buscar e identificar elementos e temas que possam orientar as visitas dos alunos ao centro de pesquisa. Visando o ensino temático, o trabalho realizou entrevistas com professores, análise do currículo, identificou aspectos científicos, sociais e tecnológicos. Podemos observar que neste artigo não há a escolha de um tema específico, por não se tratar de um grupo ou turma, e sim sobre a abordagem temática e escolha de questões.

O trabalho A04 trata da articulação teoria e prática através uma investigação colaborativa para acabar com os desafios e dificuldades do cotidiano, através de ferramentas matemáticas. No mesmo, não foi definido um tema por não se tratar de um grupo especifico. Porém, os autores argumentam sobre alguns aspectos desejáveis e relevantes durante a investigação, como a articulação da teoria e da prática e superação do ensino tradicional.

Ou seja, o artigo pretende utilizar a ferramenta da investigação colaborativa para a compreensão dos sujeitos atuantes no processo cientifico-pedagógico, além de utilizar esses dados para a análise e discussão de possibilidades deste tipo de investigação e no desenvolvimento de estudos sobre o ensino e sobre a aprendizagem matemática.

\section{Considerações Finais}

Por meio da pesquisa aqui realizada podemos conhecer um pouco mais do universo e da teoria da investigação temática de Paulo Freire. Através de uma metodologia de busca de artigos foi possível selecionar trabalhos que de alguma forma relacionavam o ensino de ciências com a questão de temas geradores e investigação temática freireana ou com o ensino temático em geral. Dessa forma, analisamos um universo de 25 artigos, e constatamos o resultado do cenário relativo a pesquisas que envolvem tema gerador, investigação e abordagem temática no contexto brasileiro. Podemos concluir que em 21 anos de publicações e periódicos analisados encontramos apenas 25 artigos que abordam o tema selecionado e que apenas 20 destes realmente incluíam o referencial de Paulo Freire em suas pesquisas, o que consideramos ser um número muito abaixo do esperado para um país que tem em Freire o título de Patrono da Educação.

Em relação ao resultado das pesquisas abordadas nos artigos: podemos concluir que uma parte dos trabalhos não se trata da busca do tema de forma a ser realizado em uma situação, escola ou comunidade específica. A discussão destes é realizada visando formas de 
superar as dificuldades de implementação, formação docente, contribuições da pesquisa e da investigação temática na realidade escolar, vida dos alunos e professores.

Outra parte dos artigos selecionados realizou de fato a investigação temática de acordo com os pressupostos freireanos e demonstrou como essa investigação foi executada, além dos resultados nas escolas e/ou nas comunidades abordadas. A maior parte desses artigos destacou os benefícios que foram obtidos através da utilização desta metodologia, como: verificar que as intervenções curriculares possibilitaram aos professores reverem suas práticas e refletirem sobre elas; observação de que o processo de aprendizagem foi percebido como algo prazeroso tanto para o estudante quanto para o professor; melhora no trabalho coletivo das instituições; maior interesse dos alunos; entre outros.

Outra parcela dos artigos selecionados também traz a questão da definição do tema gerador e da abordagem temática, porém, os mesmos não utilizam o processo de investigação e pesquisa das necessidades e problemas da comunidade em questão. Alguns temas são definidos de forma prévia pela instituição de ensino e em outras situações o contexto da comunidade ou a localidade em si definem as questões por si próprias, aos olhos de professores e pesquisadores, mas não da comunidade em si. Muitas vezes esses trabalhos justificam a não utilização da pesquisa e da utilização dos temas a partir da comunidade por alguns motivos como: o tema ser considerado por alguns um conteúdo isolado do conhecimento científico e de difícil adaptação; os professores não terem conhecimento de realizar tal ensino, por não terem tempo de planejamento ou por não estarem acostumados (visto que tiveram suas formações pautadas na educação bancária); dificuldade do trabalho coletivo; desconhecimento da perspectiva da abordagem temática; ou por simplesmente ser mais fácil continuar o ensino da forma como ele é tradicionalmente praticado.

Novamente, acreditamos que tais escolhas foram feitas pelas dificuldades de adaptação de certos temas a conteúdos específicos (como alguns artigos abordam) e mais possivelmente pelo contexto a que a pesquisa está relacionada.

Uma das dificuldades encontradas durante as análises dos artigos foi a mudança de postura que deve ser adotada pelo corpo docente para que realmente haja uma transformação. Isto porque, muitos professores já se encontram "acostumados" a apenas transmitir os conteúdos presentes no livro didático. Também constatamos que um dos principais desafios da implementação da investigação temática e do ensino problematizador através da utilização dos temas geradores é a rigidez da estrutura curricular e a necessidade de abertura e comprometimento das escolas e do corpo docente. 
A realização da teoria freireana através dos temas geradores e da investigação temática exige tempo, estudo e dedicação dos professores. Porém, a realidade da grande maioria também é um obstáculo, pois os próprios professores não dispõem de tempo hábil para realizar a investigação, e principalmente para realizar um planejamento que esteja de acordo com o tema encontrado e com os conteúdos curriculares exigidos das instituições escolares, municípios e estados. Esse fato precisa ser enfrentado pelos docentes e também observado pelos governantes, pois é uma situação que os professores não podem resolver sozinhos, é também uma luta por tempo e melhoria das condições de trabalho.

Ao finalizar este estudo podemos perceber que todas as pesquisas analisadas contribuíram para um melhor entendimento e perspectiva do trabalho de investigação de temas geradores, tanto na teoria, quanto na prática. O que podemos concluir é que a perspectiva temática ainda demanda de uma longa caminhada, exigindo um real enfrentamento e conscientização, tanto dos docentes, quanto da escola, para que seja possível sua real disseminação.

\section{Referências}

Backes, N.F., Prochnow, T.R. O tabaco utilizado como tema gerador no ensino de Química em região economicamente dependente dessa cultura. Acta Scientiae, Canoas, v.19, n.5, pp.817-831, set-out, 2017.

Bardin, L. Análise de Conteúdo. Lisboa, Portugal; Edições 70, LDA, 2009.

Britto, N.S., Silva, T.G.R. Educação do Campo: formação em ciências da natureza e o estudo da realidade. Educação e Realidade, Porto Alegre, v.40, n.3, pp.763-784, jul-set, 2015.

Caramello, G. W., Strieder, R. B., Watanabe, G., Munhoz, M. G. Articulação Centro de Pesquisa - Escola Básica: contribuições para a alfabetização científica e tecnológica. Revista Brasileira de Ensino de Física, São Paulo, v.32, n.3, pp.3401-1-3401-9, 2010.

Centa, F.G., Muenchen, C. O Despertar para uma Cultura de Participação no Trabalho com um Tema Gerador. Alexandria, Florianópolis, v.9, n.1, pp. 263-291, mai,2016. 
Costa, L. D.; Gomes, A. L. S. Concepções dos professores de ciências no ensino fundamental sobre a educação ambiental. Revista Amazônica de Ensino de Ciências, Manaus, v.8, n.17, pp.128-141, jul-dez, 2015.

Cunha, A. S., Latini, R.M. Pesquisa participante como abordagem metodológica no ensino: aprendizado de matemática e educação ambiental. Investigações em Ensino de Ciências, Niterói, v.19, n.2, pp.323-341, 2014.

Fagundes, E. M., Pinheiro, N. A. M. Considerações acerca do ensino de Ciências nos anos iniciais do Ensino Fundamental. Práxis, Volta Redonda, n.12, pp.11-26, dez, 2014.

Ferreira, M.V., Muenchen, C., Auller, D. Desafios e potencialidades em intervenções curriculares na perspectiva da abordagem temática. Revista Ensaio, Belo Horizonte, v.21, 2019.

Fonseca, K.N., Milli, J.C.L, Solino, A. P., Gehlen, S.T. Milton Santos e Paulo Freire na educação em ciências: a forma-conteúdo expressa no tema gerador. Investigações em Ensino de Ciências, Niterói, v.23, n.2, pp.331-351, AGO, 2018.

Freire, P. À Sombra desta Mangueira. São Paulo: Olho d'Água, 2000.

Freire, P. Educação como prática da liberdade. Rio de Janeiro: Paz e Terra, 1967.

Freire, P. Pedagogia do Oprimido. 17. ed. Rio de Janeiro, Paz e Terra, 1987.

Giacomini, A., Muenchen, C. Avanços alcançados por professores na implementação da abordagem temática em uma escola pública estadual do interior do RS. Educação em Revista, Belo Horizonte, v.32, n.3, pp.189-216, jul-set, 2016.

Godoy, A. S. Pesquisa qualitativa: tipos fundamentais. Revista de Administração de Empresas, São Paulo, v. 35, n. 3, pp. 20-29, mai/jun, 1995.

Guerra, A. Freitas, J., Reis, J.C., Braga, M.A. A interdisciplinaridade no ensino das ciências a partir de uma perspectiva histórico-filosófica. Caderno Brasileiro de Ensino de Física, Florianópolis, v.15, n.1. pp.32-46, abril, 1998. 
Lima, D. S., Freitas, K. C., Matos, R. A. F., Soares, M. H. F. B. Depressão e Antidepressivos: temas geradores para a discussão de conceitos químicos no nível médio de ensino. Revista Brasileira de Ensino de Ciência e Tecnologia, Curitiba, v.6, n.3, set-dez, 2013.

Melo, M.M.R., Vieira, J.M., Braga, O.C. Da xícara ao Becker: plantas medicinais como recurso didático no ensino de química. Revista de Educação, Ciências e Matemática, Rio de Janeiro, v.6, n.2, mai-ago, 2016.

Milli, J.C.L., Almeida, E.S., Gehlen, S.T. A Rede Temática e o Ciclo Temático na Busca pela Cultura de Participação na Educação CTS. Alexandria, Florianópolis, v.11, n.1, pp.71-100, mai, 2018.

Morosini, M. C. Estado de conhecimento e questões do campo científico. Educação - Revista do Cento de UFSM, Santa Maria, v.40, n.1, pp.101-116, jan-abr, 2015.

Miranda, A. C. G., Pazinato, M. S., Braibante, M. E. F. Temas geradores através de uma abordagem temática Freireana: Contribuições para o ensino de ciências. Revista de Educação, Ciências e Matemática, Rio de Janeiro, v.7, n.3, set-dez, 2017.

Muenchen, C. A Disseminação dos Três Momentos Pedagógicos: um estudo sobre as práticas docentes na região de Santa Maria/RS. 2010. 273. Tese (Doutorado em Educação Científica e Tecnológica) -UFSC, Santa Catarina.

Muenchen, C. Auller, D. Configurações curriculares mediante o enfoque CTS: desafios a serem enfrentados na educação de jovens e adultos. Ciência e Educação, Santa Maria, v.13, n.3, pp.421-434, 2007.

Nunes, L. S. R., Bomfim, A. M., Fonseca, G. R. S. Educação Ambiental crítica e arte participativa: a construção de reflexão e ação em uma escola da Baixada Fluminense. Revista de Educação em Ciências e Matemáticas, Belém, v.14, n.30, pp.42-58, jan-jul, 2018. 
Paniz, C.M., Centa, F. G., Araújo, L. B., Muenchen, C. Os três momentos pedagógicos como estruturantes de currículos: $O$ estudo da realidade e os temas geradores na educação em ciências. Reflexão e Ação, Santa Cruz do Sul, v.26, n.2, pp-249-266, abr-ago, 2018.

Silva, A. F. G. A construção do currículo na perspectiva popular crítica: das falas significativas às práticas contextualizadas. Tese de Doutorado em Educação e Currículo Pontifícia Universidade Católica de São Paulo, São Paulo, 2004.

Silva, I. M., Nicolli, A. A., Gonçalves, T. O. Possibilidades de articulação teoria-e-prática por meio da investigação colaborativa: uma proposta para o ensino de matemática. Revista de Educação em Ciências e Matemáticas, Belém, v.8, n.15,pp. 14-26, jul-dez, 2011.

Silva, L.F., Tavares, S.S., Watanabe, G., Halmenschlager, K.R., Strieder, R.B., Hunsche, S. Elementos da abordagem temática no Ensino Médio: sinalizações para formação de professoras e de professores. Ciência e Educação, Bauru, v.25, n.1, pp.145-161, 2019.

Silva, R. M., Solino, A.P., Sousa, P. S., Fonseca, K. N., Novais, E. S. P., Gehlen, S.T. Situações-limite na formação de professores de ciências na perspectiva freireana: da percepção da realidade à dimensão pedagógica. Investigações em Ensino de Ciências, Niterói, v.21, n.3, pp.127-151, dez, 2016.

Silva, R.M., Gehlen, S.T. Investigação temática na formação de professores de ciências em Pau Brasil-BA: compreensões acerca de um tema gerador. Revista Ensaio, Belo Horizonte, v.18, n.2, pp.147-169, mai-ago, 2016.

Silva, R.M., Gehlen, S.T. Investigação Temática no Contexto do Ensino de Ciências: Relações entre a Abordagem Temática Freireana e a Práxis Curricular via Tema Gerador. Revista Ensaio, Belo Horizonte, v.18, n.2, pp. 147-169, mai-ago, 2016.

Sousa, P.S., Bastos, A.P.S., Figueiredo, P.S., Gehlen, S.T. Investigação Temática no Contexto do Ensino de Ciências: Relações entre a Abordagem Temática Freireana e a Práxis Curricular via Tema Gerador. Alexandria, Florianópolis, v.7, n.2, pp.155-177, nov, 2014. 
Sousa, P.S., Bastos, A.P.S., Figueiredo, P.S., Gehlen, S.T. Tema Gerador e a Relação Universidade-Escola: Percepções de Professoras de Ciências de uma Escola Pública em Ilhéus-BA. Alexandria, Florianópolis, v.9, n.1, pp.3-29, mai, 2016.

Strieder, R.B., Caramello, G.W., Gehlen, S.T. Abordagem de temas no ensino médio: compreensões de professores de física. Revista Ensaio, Belo Horizonte, v.14, n.2, pp.153-169, ago-nov, 2012.

Torres, J.R. Educação Ambiental Crítico-Transformadora e Abordagem Temática Freireana. 2010. Tese (Doutorado em Educação Científica e Tecnológica) -UFSC, Santa Catarina.

\section{Porcentagem de contribuição de cada autor no manuscrito}

Clarissa de Oliveira Garcia França - 50\%

Marcília Elis Barcellos - 50\% 